\title{
Technical Note: The single particle soot photometer fails to reliably detect PALAS soot nanoparticles
}

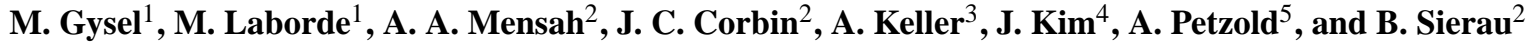 \\ ${ }^{1}$ Laboratory of Atmospheric Chemistry, Paul Scherrer Institute, 5232 Villigen PSI, Switzerland \\ ${ }^{2}$ ETH Zurich, Institute for Atmospheric and Climate Science, 8092 Zürich, Switzerland \\ ${ }^{3}$ IAST, University of Applied Sciences Northwestern Switzerland, 5210 Windisch, Switzerland \\ ${ }^{4}$ Deutsches Zentrum für Luft- und Raumfahrt, Institut für Physik der Atmosphäre, 82234 Oberpfaffenhofen, Germany \\ ${ }^{5}$ Institut für Energie- und Klimaforschung IEK-8: Troposphäre, Forschungszentrum Jülich GmbH, 52425 Jülich, Germany
}

Correspondence to: M. Gysel (martin.gysel@psi.ch)

Received: 8 June 2012 - Published in Atmos. Meas. Tech. Discuss.: 13 July 2012

Revised: 27 November 2012 - Accepted: 3 December 2012 - Published: 20 December 2012

\begin{abstract}
The single particle soot photometer (SP2) uses laser-induced incandescence (LII) for the measurement of atmospheric black carbon (BC) particles. The BC mass concentration is obtained by combining quantitative detection of $\mathrm{BC}$ mass in single particles with a counting efficiency of $100 \%$ above its lower detection limit. It is commonly accepted that a particle must contain at least several tenths of a femtogram $\mathrm{BC}$ in order to be detected by the SP2.

Here we show the result that most BC particles from a PALAS spark discharge soot generator remain undetected by the SP2, even if their BC mass, as independently determined with an aerosol particle mass analyser (APM), is clearly above the typical lower detection limit of the SP2. Comparison of counting efficiency and effective density data of PALAS soot with flame generated soot (combustion aerosol standard burner, CAST), fullerene soot and carbon black particles (Cabot Regal 400R) reveals that particle morphology can affect the SP2's lower detection limit. PALAS soot particles are fractal-like agglomerates of very small primary particles with a low fractal dimension, resulting in a very low effective density. Such loosely packed particles behave like "the sum of individual primary particles" in the SP2's laser. Accordingly, most PALAS soot particles remain undetected as the SP2's laser intensity is insufficient to heat the primary particles to their vaporisation temperature because of their small size $\left(D_{\mathrm{pp}} \approx 5-10 \mathrm{~nm}\right)$. Previous knowledge from pulsed laser-induced incandescence indicated that particle morphology might have an effect on the SP2's lower detection limit, however, an increase of the lower detection
\end{abstract}

limit by a factor of $\sim 5-10$, as reported here for PALAS soot, was not expected.

In conclusion, the SP2's lower detection limit at a certain laser power depends primarily on the total BC mass per particle for compact particles with sufficiently high effective density. By contrast, the BC mass per primary particle mainly determines whether fractal-like particles with low fractal dimension and very small primary particles are detectable, while their total BC mass has only a minor influence. This effect shifts the lower detection limit to much higher BC mass, or makes them completely undetectable. Consequently, care has to be taken when using the SP2 in applications dealing with loosely packed particles that have very small primary particles as building blocks.

\section{Introduction}

Atmospheric black carbon (BC) particles are a concern due to their impact on climate and their adverse health effects (Shindell et al., 2012). Nevertheless, the measurement of the number and the mass concentration of atmospheric BC particles remains a challenge, as interference from organic carbon and inorganic aerosol components often causes substantial measurement uncertainty (e.g. Schmid et al., 2001; Müller et al., 2011). Recently, the single particle soot photometer (SP2; Stephens et al., 2003), which uses laser-induced incandescence (LII) to detect BC, was developed. The SP2 makes quantitative measurements of $\mathrm{BC}$ mass concentrations 
possible, as it combines quantitative detection of $\mathrm{BC}$ mass in single particles with a counting efficiency of $100 \%$ above its lower detection limit (Schwarz et al., 2010; Laborde et al., 2012b). A further key feature is that the BC mass measurement is independent of particle mixing state (Moteki and Kondo, 2007; Slowik et al., 2007; Laborde et al., 2012b).

The lower detection limit for successful counting of BC particles by the SP2's incandescence detector, expressed in terms of minimal BC mass in a single particle, depends both on physical limitations of the detection technique as well as instrument parameters chosen by the operator. BC particles fail to heat to their vaporisation temperature $(\sim 4000 \mathrm{~K})$, a requirement for proper detection, if their BC mass is too small or the laser intensity is too low (Schwarz et al., 2010). The assumption currently made among SP2 users is that the lower detection limit of the SP2 at a certain laser intensity is given by the total BC mass in a particle, largely independent of coatings with non-refractory matter and the particle's morphology. However, during a recent experiment we observed a counter-example to the assumption that particle morphology is unimportant for successful BC particle detection.

The primary aim of the "BC-act" campaign was comparing and characterising different $\mathrm{BC}$ mass and light absorption measurement techniques with different types of $\mathrm{BC}$ aerosols. The investigated $\mathrm{BC}$ particle sources include, among others, a PALAS GFG 1000 soot generator (Helsper et al., 1993), which applies spark discharge to produce pure BC particles. Here we present the result that the SP2's incandescence detector fails to reliably detect PALAS soot particles, even if their BC mass is substantially higher than the normal lower detection limit of the SP2. This result is put in the context of effective density measurements, thereby also discussing implications for the measurement of ambient $\mathrm{BC}$ particles using the SP2.

\section{Methods}

\subsection{Experimental setup}

The experiments were performed in the framework of the campaign "BC-act" carried out at ETH Zurich in January 2012. The aim of the experiments was to physically and chemically characterise different types of laboratorygenerated soot particles, and to intercompare diverse $\mathrm{BC}$ measurement techniques.

The experimental setup applied in this study is shown in Fig. 1. The soot aerosol obtained from different sources was diluted and fed into a vessel with a residence time of $\sim 30 \mathrm{~min}$. The sample taken from the vessel was further diluted and neutralized using ${ }^{210}$ Po bipolar chargers (two chargers were applied in series in order to ensure charge equilibration at the relatively high flow rates applied in this study). A differential mobility analyser (DMA; TSI model 3080L), was used to size-select the soot particles. Parti-

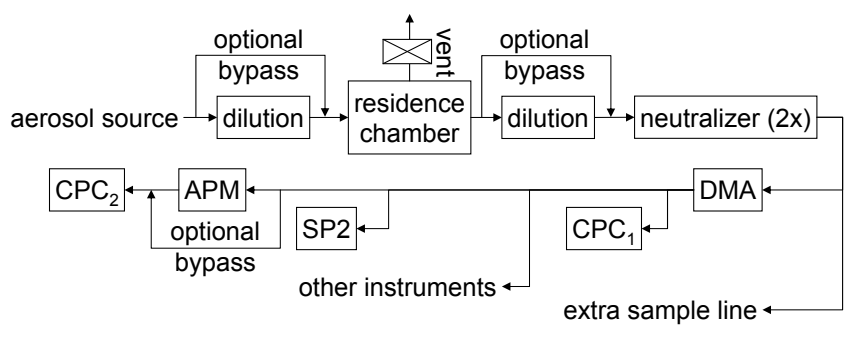

Fig. 1. Experimental setup for the measurement of effective density and SP2 counting efficiency of laboratory-generated soot particles.

cle number size distributions were measured for each soot sample by operating the DMA and a condensation particle counter (CPC; TSI model 3010; labelled as $\mathrm{CPC}_{1}$ in Fig. 1) as a scanning mobility particle sizer (SMPS). Most of the time the DMA was set to select particles of a fixed size for further experimental characterisation of soot particles with a well-defined electrical mobility diameter $\left(D_{\mathrm{mob}}=125,200\right.$, 305 or $500 \mathrm{~nm})$.

\subsection{Single particle soot photometer}

The single particle soot photometer (SP2; Stephens et al., 2003) is manufactured by Droplet Measurement Technologies, Boulder USA, and uses a continuous-wave highintensity intracavity laser (Nd: YAG solid state crystal at a wavelength of $\lambda=1064 \mathrm{~nm}$ ) to detect refractory black carbon (rBC; henceforth simply referred to as BC) by laserinduced incandescence. Key features of the SP2 are quantitative measurement of $\mathrm{BC}$ mass in single particles with a counting efficiency of $\sim 100 \%$ above its lower detection limit.

Light absorbing particles are heated by the strong detection laser on the time scales of microseconds. Any nonrefractory components of the particle evaporate first, leaving the most refractory component behind (BC in our case). The temperature of the bare $\mathrm{BC}$ core increases further, leading to a steep increase of the thermal radiation, until the vaporisation temperature of $\mathrm{BC}$ is reached. From that moment, the temperature of the $\mathrm{BC}$ core stabilises while gradual mass loss occurs due to evaporation. Consequently, the thermal radiation also decreases. The SP2 records the thermal radiation of single particles with high time resolution. The presence of an incandescence signal is used to count the BC-containing particles; the peak amplitude of the incandescence signal, which occurs at a well-defined temperature and before evaporation of the $\mathrm{BC}$ core, is used to quantify the $\mathrm{BC}$ mass in single particles.

An SP2 with standard detector configuration from the manufacturer was employed in this study. It uses a H6779 photomultiplier tube (PMT, Hamamatsu Inc.) behind a Schott KG-5 filter to measure broadband incandescence signals and a H6779 PMT behind Schott KG-5 and RG-630 filters to measure narrowband incandescence 
signals. All BC measurements (counting and BC mass quantification) presented in this study are based on the broadband incandescence signal. The narrowband incandescence signal was only used to check the laser intensity as discussed in Sect. 3. The position sensitive detector (PSD) of the SP2 uses a C30927EH-01 quadrant array avalanche photodiode (Perkin-Elmer) behind a Schott RG-850 filter to determine the particle's position in the laser beam from the elastically scattered light (Gao et al., 2007).

The SP2 was prepared following the instructions given in Laborde et al. (2012b), namely assuring sufficient laser intensity, Gaussian laser beam shape $\left(\mathrm{TEM}_{00}\right.$ mode) and careful alignment of the particle beam to the centre of the laser beam, as further detailed in Sect. 3. Fullerene soot obtained from Alpha Aesar (lot\# FS12S011), the recommended SP2 calibration standard (Moteki and Kondo, 2010; Laborde et al., 2012a; Baumgardner et al., 2012), was used to calibrate the SP2 as described in Laborde et al. (2012a).

\subsection{Aerosol particle mass analyser}

The mass and effective density of the size-selected soot particles was determined with an aerosol particle mass analyser (APM; Kanomax APM-II model 3601; Ehara et al., 1996), using the approach previously described in the literature (e.g. Park et al., 2003; Olfert et al., 2007; Gysel et al., 2011). Particle mass analysers select particles according to their mass-to-charge ratio by balancing the electrostatic and centrifugal forces which act on particles introduced into a thin annular space formed between rotating cylindrical electrodes. The APM voltage was scanned while holding the APM rotational speed and the DMA voltage constant in order to determine the mass of the size-selected particles by simultaneous counting of the particle concentration at the APM outlet using a CPC (TSI model 3022; labelled as $\mathrm{CPC}_{2}$ in Fig. 1). The mass, $m$, of the particles was determined from the APM voltage, $V_{\text {peak }}$, at which the measured number concentration is at maximum (Ehara et al., 1996):

$m=\frac{q V_{\text {peak }}}{\omega^{2} r_{\mathrm{c}}^{2} \ln \left(r_{\mathrm{o}} / r_{\mathrm{i}}\right)}$,

where $q$ is the charge of the particle, $r_{\mathrm{i}}$ and $r_{\mathrm{o}}$ are the inner and the outer radii of the cylinders, $\omega$ is the rotational speed of the cylinders (equal for the inner and outer cylinders in the APM), and $r_{\mathrm{c}}=\left(r_{\mathrm{i}}+r_{\mathrm{o}}\right) / 2$. The DMA and the APM were operated at sufficiently high resolution such that the potential bias of $V_{\text {peak }}$ due to interference from multiply charged particles was smaller than the measurement accuracy. This was verified using the SP2 data, which make it possible to distinguish between singly and multiply charged particles. The effective density, $\rho_{\text {eff }}$, was calculated from the mass, $m$, and the mobility diameter, $D_{\mathrm{mob}}$, using the following equation (first variant of effective density definitions described in DeCarlo et al., 2004):

$\rho_{\text {eff }}=\frac{6 m}{\pi D_{\text {mob }}^{3}}$.

Certified polystyrene microsphere size standards (PSL spheres; obtained from Duke Scientific Corporation, Palo Alto, USA and from BS-Partikel Gmbh, Wiesbaden, Germany) were used to verify accurate operation of the DMA and the APM, resulting in an accuracy of around $\pm 10 \%$ for the effective density measurements.

\subsection{Soot particle generation}

Spark discharge soot was produced using a commercial PALAS GFG 1000 soot generator (Helsper et al., 1993). The PALAS GFG was operated at a spark frequency of $75 \mathrm{~Hz}$ between the graphite electrodes, using Argon as carrier gas and without internal dilution flow. The number size distribution of the spark discharge soot, hereafter referred to as PALAS soot, peaked at a mobility diameter of $\sim 130 \mathrm{~nm}$.

Flame-generated soot was produced by a co-flow diffusion flame of propane and synthetic air using a combustion aerosol standard burner (CAST; model CAST-00-4; Jing Ltd). The CAST burner was operated with a rich and a lean mixture in order to obtain soot particles with different ratios of organic carbon $(\mathrm{OC})$ to elemental carbon $\left(\mathrm{EC}^{1}\right)$. An equivalence ratio of $\phi=0.85$ (carbon-to-oxygen ratio $\mathrm{C} / \mathrm{O}=0.25$ ) was chosen for the experiment on 25 January 2012, resulting in almost pure EC particles (Schnaiter et al., 2006), henceforth referred to as CAST "black" soot. An equivalence ratio of $\phi=1.36(\mathrm{C} / \mathrm{O}=0.41)$ was chosen for the experiment on 27 January 2012, resulting in soot particles containing EC and a substantial fraction of OC (Schnaiter et al., 2006), henceforth referred to as CAST "brown" soot.

Soot particles were also produced from two commercial soot powders, which were dispersed in MilliQ water, nebulised using a Collison type atomizer and dried with a silica gel diffusion dryer.

Cabot Regal 400R powder was obtained from Cabot Corporation. Regal Black, as we name it henceforth, is composed of carbon black, a form of amorphous carbon, and it is the material currently recommended for calibration of Aerodyne Research's soot particle aerosol mass spectrometer (SP-AMS; Onasch et al., 2012). Our sample originates from the batch (lot\# GP-3901), which is centrally stored and distributed by Aerodyne Research to assure consistent SP-AMS calibration.

Fullerene soot "as produced" powder was obtained from Sigma Aldrich (lot\# MKBB8240V). Fullerene soot is a form

\footnotetext{
${ }^{1}$ The terms EC, BC and $\mathrm{rBC}$ are operationally defined based on the applied measurement technique (thermal-optical, light absorption and laser-induced incandescence, respectively). However, they synonymously refer to pure carbon (e.g. Kondo et al., 2011), which is the most refractory and light absorbing component of carbonaceous combustion particles.
} 
of amorphous carbon containing $\sim 10 \%$ fullerenes and it is the material recommended for calibration of Droplet Measurement Technologies' SP2 (Baumgardner et al., 2012).

\section{Results and discussion}

\subsection{Counting efficiency}

The counting efficiency of the SP2 for BC particles was compared against $\mathrm{CPC}_{2}$ (Fig. 1). The APM was bypassed for this purpose, such that the SP2 and the CPC measured the same size-selected sample of BC particles. The CPC counts all particles while the SP2's incandescence detector selectively counts BC-containing particles. The counting efficiency calculated from the ratio of the CPC and SP2 number concentrations is only meaningful if every particle of the investigated aerosol contains a BC core. This condition is fulfilled for the CAST soot and PALAS soot aerosols. Nebulisation of aqueous dispersions of fullerene soot and Regal Black samples produces BC-containing particles as well as very small residual particles from those droplets not containing a $\mathrm{BC}$ core. However, this mode of residual particles did not extend up to the mobility diameters selected here, such that every particle of the size-selected fullerene soot and Regal Black samples was expected to contain BC.

The results of the counting efficiency measurements as a function of the particle's mobility diameter are shown in Fig. 2a. The SP2 has, within experimental uncertainty, a detection efficiency of $100 \%$ for fullerene soot, Regal Black, CAST "black" soot and CAST "brown" soot in the mobility diameter range of $125-500 \mathrm{~nm}$. This is consistent with previous literature reports on the SP2's detection efficiency (Schwarz et al., 2010; Laborde et al., 2012b). However, the unexpected result is a detection efficiency as low as $0-12 \%$ by the incandescence detector for the PALAS soot at mobility diameters between $200-500 \mathrm{~nm}$ when operating the SP2 at equal laser power as for the other BC types.

PALAS soot can be brought to incandescence by using a pulsed laser (Robers et al., 1988) and it can be vaporised by the desorption/ionization laser of the aerosol time-of-flight mass spectrometer (ATOFMS; Su et al., 2005). These two methods apply laser pulses of much higher intensity than that of the continuous-wave laser applied in the SP2. This indicates that sufficient laser intensity plays an important role for reliable detection of PALAS soot by laser-induced incandescence, as further detailed in Sect. 3.3.

\subsection{Effective density}

Figure $2 b$ shows the effective density of the investigated soot types as a function of the particle's mobility diameter. The effective density of all samples decreases with increasing particle size and it is clearly below the void-free material density of BC $\left(\sim 1800 \mathrm{~kg} \mathrm{~m}^{-3}\right.$; Mullins and Williams, 1987; Park et al., 2004). This indicates fractal-like or flaky par- ticle structures. The values reported here for the fullerene soot are in the range of previous literature data (Moteki and Kondo, 2010; Gysel et al., 2011), though the fullerene soot sample investigated in this study was obtained from a different producer. The size-dependent effective density measured for Regal Black is identical to that previously described in the literature for the same batch (Onasch et al., 2012). This shows that the mass of size-selected Regal Black particles can reliably be calculated from their mobility diameter, at least for the batch which is distributed by Aerodyne Research as calibration standard for the SP-AMS. The effective density of the CAST "black" soot is slightly lower than that of the CAST "brown" soot, consistent with previous reports of the influence of fuel equivalence ratio (Slowik et al., 2004). The PALAS soot's effective density is $\sim 4-10$ times lower compared to that of all other investigated samples. This gives a first hint that particle morphology might play a role regarding the SP2's counting efficiency issue for the PALAS soot. However, counting efficiency may have dropped below unity for several other reasons, as follows.

\subsection{Detection of PALAS soot}

Schwarz et al. (2010) identified sufficiently high laser intensity as a crucial factor for achieving optimal counting efficiency with the SP2. BC particles have to reach their vaporisation temperature for proper detection by the SP2. This is only achieved if the energy uptake rate from absorption of the laser light exceeds the energy loss rate across the whole temperature range passed by the particle until eventually reaching the vaporisation temperature of the $\mathrm{BC}$ core. Heat conduction to the surrounding air is the main energy loss term during the phase when the bare $\mathrm{BC}$ core approaches vaporisation, while thermal radiation gives a negligible contribution at atmospheric pressure (Kuhlmann et al., 2006). The diameter of the BC core influences the competition between absorption of the laser light and heat conduction to the surrounding air, which are proportional to $\sim D^{3}$ and to $\sim D^{2}$ (or less), respectively (Bladh et al., 2008). Consequently the ratio of energy loss rate to energy uptake rate increases with decreasing BC mass per particle, thereby imposing the physical limitation for the lower detection limit that can be achieved with the SP2 at a certain laser intensity. Schwarz et al. (2010) also demonstrated two methods to identify the threshold laser intensity for proper BC particle detection by the SP2. Their colour ratio method has been applied to the SP2 employed in this study, in order to ensure sufficient laser intensity for the detection of particles containing at least $1 \mathrm{fg} \mathrm{BC}$. The fact that unit detection efficiency was achieved within uncertainty for all monodisperse samples of fullerene soot, Regal Black, CAST "black" soot and CAST "brown" soot, covering the range down to a total particle mass of $\sim 1 \mathrm{fg}$ (Fig. 3), confirms that sufficient laser intensity was available for the detection of "normal" BC particles. This holds even for singly charged particles of the smallest sample of the 


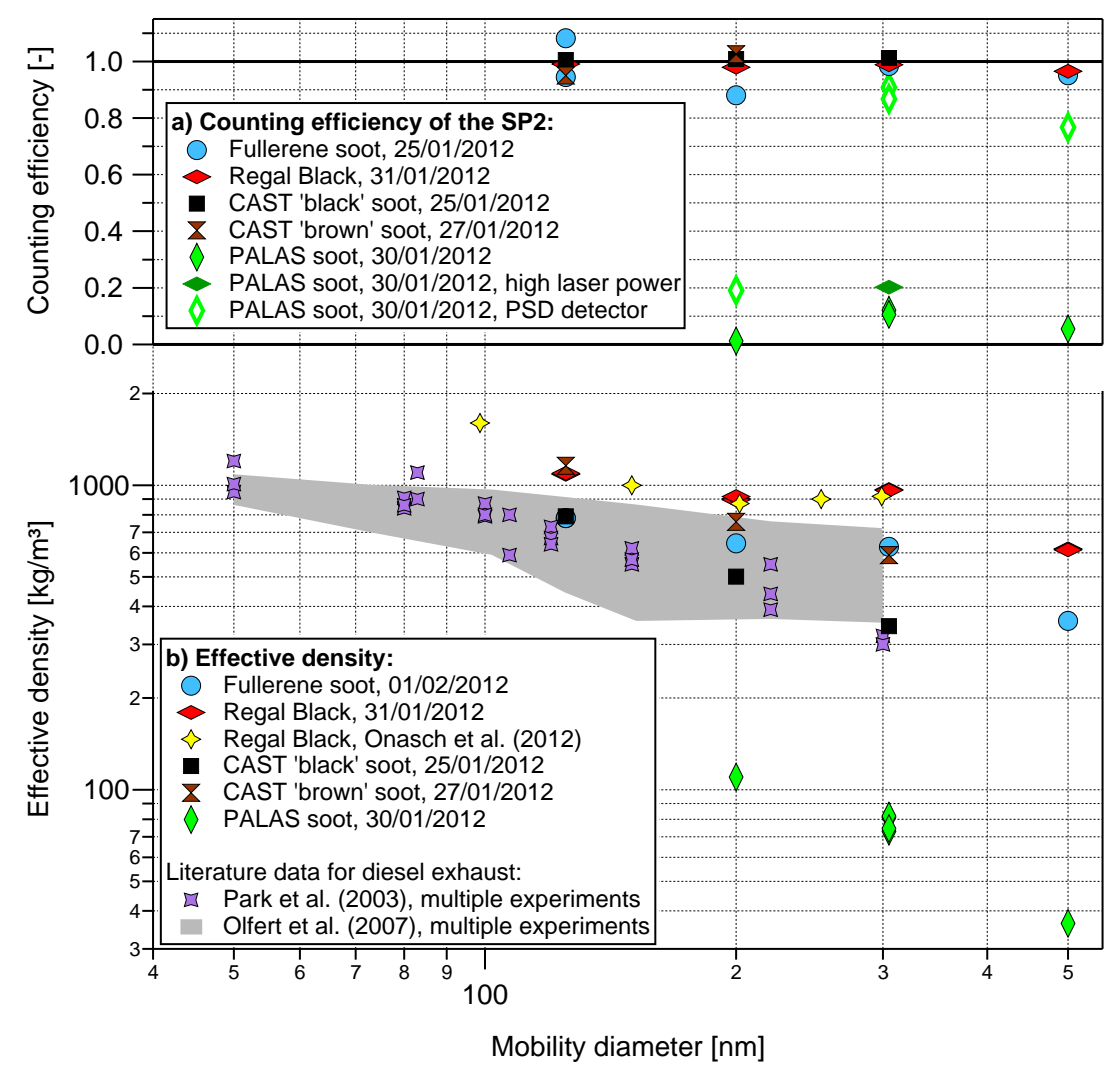

Fig. 2. (a) Counting efficiency of SP2's incandescence detector (for different BC samples) and position sensitive detector (PSD; for PALAS soot only). (b) Effective density as a function of the particle's mobility diameter. Literature data of Regal Black's effective density are from Onasch et al. (2012). Effective density data of diesel exhaust soot are from Park et al. (2003) and Olfert et al. (2007).

organic-rich CAST "brown" soot $\left(D_{\mathrm{mob}}=125 \mathrm{~nm}\right)$, which contained on average as little as $\sim 0.45 \mathrm{fg} \mathrm{BC}$ per particle (SP2 measurement) at an average particle mass of $\sim 1.2 \mathrm{fg}$ (APM measurement).

The width of the particle beam directed through the SP2's laser is approximately equal to the width of the range across which the Gaussian laser beam has $\geq 70 \%$ of it's maximal intensity (Schwarz et al., 2010). Careful alignment of the particle beam to the centre of the laser beam is a critical factor for achieving optimal counting efficiency. Misalignment causes a drop in counting efficiency for small BC particles (Laborde et al., 2012b), as they are exposed to insufficient laser intensity when crossing the laser beam at its edges. At the beginning of the study, the SP2 was carefully aligned following the standard alignment procedures (Droplet Measurement Technologies, 2012). Successful alignment is confirmed by the fact that a counting efficiency of $\sim 100 \%$ is achieved for the small particles of all investigated BC samples except for the PALAS soot (Fig. 3).

The divergence of the particle beam could possibly be larger for the PALAS soot particles with a very low effective density than for the other BC samples with a higher effective density, thereby causing a similar effect as a misalignment. However, no substantial influence of particle size/morphology is expected for the concentric-nozzle jet system applied in the SP2. Furthermore, the bigger sizes of the PALAS soot particles $\left(D_{\mathrm{mob}}=305\right.$ and $\left.500 \mathrm{~nm}\right)$ are properly counted by the SP2's position sensitive detector (open green symbols in Fig. 2a), which detects elastically scattered light (while the smallest investigated PALAS soot particles fall below the normal lower detection limit of the position sensitive detector, such that only the multiply charged particles, $\sim 20 \%$ of the total number, are counted at the nominal size of $D_{\mathrm{mob}}=200 \mathrm{~nm}$ ). This shows that the particle beam has a smaller width than the laser beam also for PALAS soot particles. Thus, the hypothesis of larger particle beam divergence can be discarded.

The SP2 records the signals from a particle only if at least one signal crosses the trigger threshold for data storage, which is set in the data acquisition software. The position sensitive detector's signal triggered storage of the signals from all detectors for all PALAS soot particles with $D_{\mathrm{mob}}=305$ or $500 \mathrm{~nm}$. The total number concentration of detected particles agreed within uncertainty with that measured by the CPC (Fig. 2a). This proves that neither coincidence nor duty cycle problems caused the low counting efficiency. On the contrary, the signal from the broadband incandescence detector was recorded for all particles but it 


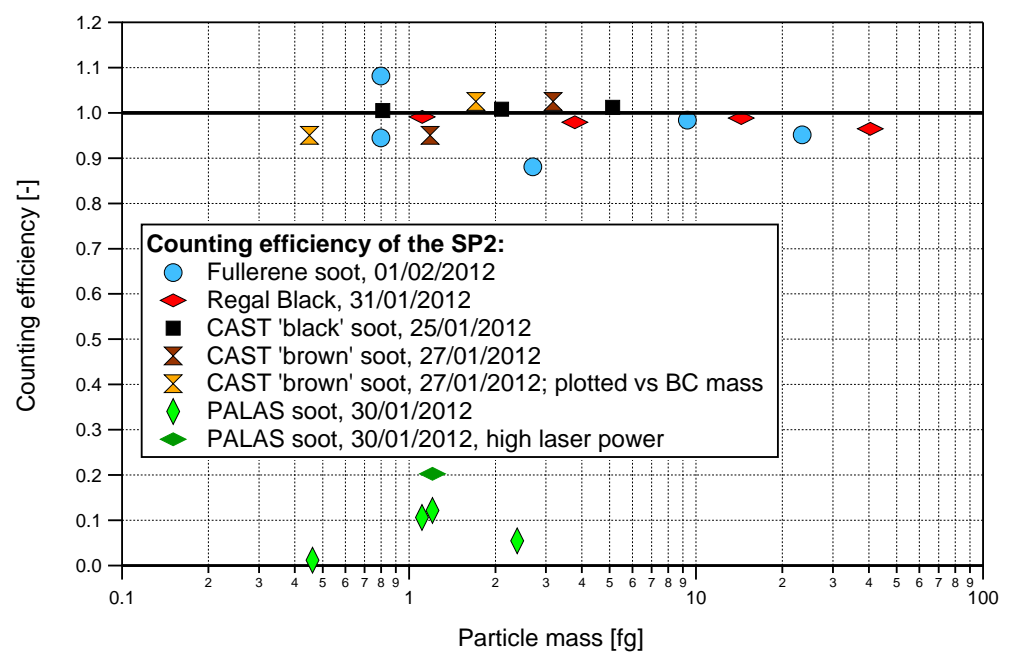

Fig. 3. Counting efficiency of SP2's incandescence detector relative to CPC for different soot samples as a function of particle mass determined by the APM. The CAST "brown" soot is additionally shown as a function of the mean BC mass per particle determined by the SP2.

contained only baseline noise without a true incandescence peak for most PALAS soot particles. Thus failure of signal triggering or any other issue with the data acquisition software can be excluded.

The nanocrystalline structure differs between different BC types and with that also their chemical reactivity. PALAS soot has been shown to be the most reactive BC material among several BC types, and this results in a lower combustion temperature during thermal(-optical) analysis (e.g. Schmid et al., 2011; Schuster et al., 2011). The question to be answered here is whether the PALAS soot particles lose a substantial fraction of their mass through combustion before they reach their vaporisation temperature in the SP2. The heating rate of BC particles in the SP2 is around nine orders of magnitude faster than that applied in thermal(optical) analysis, which leaves very little time for combustion. Analysis of the time-resolved scattering signal of the non-incandescent PALAS soot particles revealed that the BC in these particles does neither evaporate nor react away in substantial amounts, while the particles cross the laser beam. Consequently, the high chemical reactivity of PALAS soot can be excluded as a reason for its missing incandescence signal.

The monodisperse samples of PALAS soot particles had a much lower effective density than the other BC samples (Fig. 2b) but the average mass of the singly charged particles still reached up to $2.4 \mathrm{fg}$ per particle at the largest size (Fig. 3). PALAS soot particles contain mainly BC, though up to $25 \%$ organic contamination have previously been identified (Roth et al., 2004; Schneider et al., 2006). The BC mass range covered in this study for the PALAS soot remains above the BC mass limit, below which counting efficiency normally drops for the incandescence detector, even when potential organic contamination is taken into account.
The fact that the counting efficiency was as low as $5 \%$ for the PALAS soot particles with a mass of $2.4 \mathrm{fg}$, whereas it was $\sim 100 \%$ for particles with similar and even clearly lower $\mathrm{BC}$ mass content for all other investigated soot types, reveals that $\mathrm{BC}$ mass per particle cannot be the only parameter determining the lower detection limit of the SP2 at a certain laser intensity.

The morphology of the particles can obviously have a considerable influence on the SP2's detection efficiency too, as already known from pulsed laser-induced incandescence (Bladh et al., 2011). The PALAS soot particles are fractallike agglomerates (see e.g. Kulkarni et al., 2011, for details) with a fractal dimension in the range of $\sim 1.7-2.1$ and with an extremely small primary particle diameter of $D_{\mathrm{pp}} \approx 5-$ $10 \mathrm{~nm}$ (e.g. Helsper et al., 1993; Weingartner et al., 1997; Mikhailov et al., 2001; Wentzel et al., 2003; Schneider et al., 2006), which is consistent with very low effective density as reported above (Fig. 2b). Light absorption by fractal-like particles with fractal dimensions of $\sim 2$ or lower is, for small size parameters of the primary particles $\left(x_{\mathrm{pp}}=\pi D_{\mathrm{pp}} / \lambda\right)$, approximately equal to the sum of the light absorption by the individual primary particles (Mulholland and Mountain, 1999; Schnaiter et al., 2003). Similarly, heat conduction to the surrounding air is approximately equal to the sum of the heat conduction by the individual primary particles (Bladh et al., 2011). Consequently, for particles with a low fractal dimension and very small primary particles, the physical limit for reaching the vaporisation temperature at a certain laser power depends, for the most part, on the primary particle size, with a minor influence of the total $\mathrm{BC}$ mass in the agglomerate. This effect shifts the lower detection limit to much higher BC mass, or makes them completely undetectable. A more detailed analysis of the light scattering and incandescence signals shows that unit detection efficiency was actually 
achieved for the largest multiply charged PALAS soot particles with a BC mass of $\geq 4-6 \mathrm{fg}$. This corresponds to an increase of the lower detection limit by a factor of $\sim 5-10$.

Varying the laser power provided further evidence that the unreliable detection of small PALAS soot particles is caused by the influence of particle morphology on the threshold laser intensity rather than chemical reactivity effects. An increase of the counting efficiency from $\sim 12 \%$ to $\sim 20 \%$ (dark green diamond in Figs. 2a and 3) was achieved for PALAS soot particles with a mobility diameter of $D_{\mathrm{mob}}=305 \mathrm{~nm}$, by increasing the laser power as much as possible $(\sim 45 \%$ higher intensity).

The fullerene soot and CAST soot particles are also fractal-like agglomerates, but they had higher effective densities (Fig. 2b) and larger primary particle diameters of $\sim 50 \mathrm{~nm}$ (Moteki et al., 2009) and $\sim 15-30 \mathrm{~nm}$ (e.g. Schnaiter et al., 2006; Bladh et al., 2011), respectively. Although individual primary particles of such sizes remain below the SP2's typical lower detection limit, the fullerene soot and CAST soot agglomerates are sufficiently compact such that their mass specific heat conduction to the surrounding air is sufficiently reduced, compared to that of their primary particles, to bring agglomerates with a total mass of $\geq 1 \mathrm{fg}$ above the SP2's incandescence threshold.

\subsection{Implications for atmospheric applications}

The SP2's counting efficiency issue is relevant for applications involving PALAS soot. The key question regarding atmospheric applications of the SP2 is, whether the lower detection limit for unit counting efficiency for diesel soot particles is similar to that for flame-generated soot and fullerene soot, which have been used in previous studies addressing counting efficiency. The mass absorption coefficient of diesel soot is a factor of $\sim 2$ larger than that of PALAS soot (Schnaiter et al., 2003), which can be explained by the larger primary particle size and the higher degree of ordered nanocrystalline graphitic structures of diesel soot compared to PALAS soot (Mulholland and Mountain, 1999; Wentzel et al., 2003; Schnaiter et al., 2003). The specific energy loss rate by heat conduction to the surrounding air is expected to be smaller for diesel soot than PALAS soot, as diesel soot has substantially higher effective density (Fig. 2b; Park et al., 2003; Olfert et al., 2007), indicating a lower surface-tovolume ratio. These two factors decrease the threshold laser power for proper detection by the SP2 of diesel soot compared to PALAS soot. Effective density values of diesel soot reported in the literature (Park et al., 2003; Olfert et al., 2007) are similar to those of CAST soot (Fig. 2b). The primary particle diameter of diesel soot agglomerates is in the range of $\sim 25 \mathrm{~nm}$ (Weingartner et al., 1997; Wentzel et al., 2003), which is also comparable to CAST soot. Therefore, it can be expected that the SP2 is able to detect diesel soot particles with a similar lower detection limit as for the CAST soot.
McMeeking et al. (2011) operated an SP2 downstream of a hygroscopicity tandem differential mobility analyser (HTDMA; see e.g. Swietlicki et al., 2008, for details on the HTDMA technique), in order to determine the number fraction of $\mathrm{BC}$-containing particles as a function of the hygroscopic growth factor (HGF) of size-selected particles $\left(D_{\text {mob }}=193 \mathrm{~nm}\right)$ in urban air at Manchester, UK. The fact that they detected $\mathrm{BC}$ in every particle in the less hygroscopic mode $(\mathrm{HGF} \leq 1.2)$ gives direct evidence of unit detection efficiency by the SP2 for freshly emitted diesel soot particles, which are commonly associated with the less hygroscopic mode in urban environments (this applies for a mass of $\sim 1.9 \mathrm{fg} \mathrm{BC}$ per particle, assuming an effective density of $\sim 500 \mathrm{~kg} \mathrm{~m}^{-3}$ at $D_{\text {mob }}=193 \mathrm{~nm}$ ). Nevertheless, it cannot be excluded that a minor subset of atmospheric BC particles, with a morphology at the lower end of effective density and primary particle size, can remain undetected by the SP2 despite containing more $\mathrm{BC}$ mass than the commonly accepted lower detection limit of the SP2.

\section{Conclusions}

This study reveals that the SP2 is unable to reliably detect PALAS soot particles with the incandescence detector, even if they contain substantially more BC mass than the typical lower detection limit of the SP2. This could be attributed to the morphology of the PALAS soot particles, which are fractal-like agglomerates of very small primary particles with a low fractal dimension, resulting in a very low effective density. Such loosely packed particles behave like "the sum of individual primary particles" in the SP2's laser. Accordingly, most PALAS soot particles remain undetected as the SP2's laser intensity is insufficient to heat the primary particles to their vaporisation temperature because of their small size $\left(D_{\mathrm{pp}} \approx 5-10 \mathrm{~nm}\right)$. Previous knowledge from pulsed laser-induced incandescence indicated that particle morphology might have an effect on the SP2's lower detection limit, however, an increase of the lower detection limit by a factor of $\sim 5-10$, as reported here for PALAS soot, was not expected.

In conclusion, the SP2's lower detection limit at a certain laser power depends primarily on the total $\mathrm{BC}$ mass per particle for compact particles with sufficiently high effective density. By contrast, the $\mathrm{BC}$ mass per primary particle mainly determines whether fractal-like particles with low fractal dimension and very small primary particles are detectable, while their total $\mathrm{BC}$ mass has only a minor influence. This effect shifts the lower detection limit to much higher BC mass, or makes them completely undetectable. Consequently, care has to be taken when using the SP2 in applications dealing with loosely packed particles that have very small primary particles as building blocks. 
Acknowledgements. Financial support was received from the Swiss National Science Foundation (grant no. 200021_132199/1).

Edited by: W. Maenhaut

\section{References}

Baumgardner, D., Popovicheva, O., Allan, J., Bernardoni, V., Cao, J., Cavalli, F., Cozic, J., Diapouli, E., Eleftheriadis, K., Genberg, P. J., Gonzalez, C., Gysel, M., John, A., Kirchstetter, T. W., Kuhlbusch, T. A. J., Laborde, M., Lack, D., Müller, T., Niessner, R., Petzold, A., Piazzalunga, A., Putaud, J. P., Schwarz, J., Sheridan, P., Subramanian, R., Swietlicki, E., Valli, G., Vecchi, R., and Viana, M.: Soot reference materials for instrument calibration and intercomparisons: a workshop summary with recommendations, Atmos. Meas. Tech., 5, 1869-1887, doi:10.5194/amt-51869-2012, 2012.

Bladh, H., Johnsson, J., and Bengtsson, P.-E.: On the dependence of the laser-induced incandescence (LII) signal on soot volume fraction for variations in particle size, Appl. Phys. B, 90, 109125, doi:10.1007/s00340-007-2826-0, 2008.

Bladh, H., Johnsson, J., Rissler, J., Abdulhamid, H., Olofsson, N.-E., Sanati, M., Pagels, J., and Bengtsson, P.-E.: Influence of soot particle aggregation on time-resolved laserinduced incandescence signals, Appl. Phys. B, 104, 331-341, doi:10.1007/s00340-011-4470-y, 2011.

DeCarlo, P. F., Slowik, J. G., Worsnop, D. R., Davidovits, P., and Jimenez, J. L.: Particle morphology and density characterization by combined mobility and aerodynamic diameter measurements. Part 1: Theory, Aerosol Sci. Technol., 38, 1185-1205, doi:10.1080/027868290903907, 2004.

Droplet Measurement Technologies: Single Particle Soot Photometer (SP2) - Operator Manual - DOC-0171 - Revision G-2, 2012.

Ehara, K., Hagwood, C., and Coakley, K. J.: Novel method to classify aerosol particles according to their mass-to-charge ratio Aerosol particle mass analyser, J. Aerosol Sci., 27, 217-234, doi:10.1016/0021-8502(95)00562-5, 1996.

Gao, R. S., Schwarz, J. P., Kelly, K. K., Fahey, D. W., Watts, L. A., Thompson, T. L., Spackman, J. R., Slowik, J. G., Cross, E. S., Han, J.-H., Davidovits, P., Onasch, T. B., and Worsnop, D. R.: A novel method for estimating lightscattering properties of soot aerosols using a modified singleparticle soot photometer, Aerosol Sci. Technol., 41, 125-135, doi:10.1080/02786820601118398, 2007.

Gysel, M., Laborde, M., Olfert, J., Subramanian, R., and Gröhn, A.: Effective density of Aquadag and fullerene soot black carbon reference materials used for SP2 calibration, Atmos. Meas. Tech., 4, 2851-2858, doi:10.5194/amt-4-2851-2011, 2011.

Helsper, C., Mölter, W., Löffler, F., Wadenpohl, C., Kaufmann, S., and Wenninger, G.: Investigations of a new aerosol generator for the production of carbon aggregate particles, Atmos. Environ., 27A, 1271-1275, doi:10.1016/0960-1686(93)90254-V, 1993.

Kondo, Y., Sahu, L., Moteki, N., Khan, F., Takegawa, N., Liu, X., Koike, M., and Miyakawa, T.: Consistency and traceability of black carbon measurements made by laser-induced incandescence, thermal-optical transmittance, and filter-based photoabsorption techniques, Aerosol Sci. Technol., 45, 295-312, doi:10.1080/02786826.2010.533215, 2011.
Kuhlmann, S.-A., Reimann, J., and Will, S.: On heat conduction between laser-heated nanoparticles and a surrounding gas, J. Aerosol Sci., 37, 1696-1716, doi:10.1016/j.jaerosci.2006.06.009, 2006.

Kulkarni, P., Baron, P. A., and Willeke, K.: Aerosol Measurement - Principles, Techniques, and Applications, Wiley, Hoboken, 3rd Edn., doi:10.1002/9781118001684, p. 514ff, 2011.

Laborde, M., Mertes, P., Zieger, P., Dommen, J., Baltensperger, U., and Gysel, M.: Sensitivity of the Single Particle Soot Photometer to different black carbon types, Atmos. Meas. Tech., 5, 10311043, doi:10.5194/amt-5-1031-2012, 2012a.

Laborde, M., Schnaiter, M., Linke, C., Saathoff, H., Naumann, K.H., Möhler, O., Berlenz, S., Wagner, U., Taylor, J. W., Liu, D., Flynn, M., Allan, J. D., Coe, H., Heimerl, K., Dahlkötter, F., Weinzierl, B., Wollny, A. G., Zanatta, M., Cozic, J., Laj, P., Hitzenberger, R., Schwarz, J. P., and Gysel, M.: Single Particle Soot Photometer intercomparison at the AIDA chamber, Atmos. Meas. Tech., 5, 3077-3097, doi:10.5194/amt-5-3077-2012, 2012b.

McMeeking, G. R., Good, N., Petters, M. D., McFiggans, G., and Coe, H.: Influences on the fraction of hydrophobic and hydrophilic black carbon in the atmosphere, Atmos. Chem. Phys., 11, 5099-5112, doi:10.5194/acp-11-5099-2011, 2011.

Mikhailov, E. F., Vlasenko, S. S., Krämer, L., and Niessner, R.: Interaction of soot aerosol particles with water droplets: influence of surface hydrophilicity, J. Aerosol Sci., 32, 697-711, doi:10.1016/S0021-8502(00)00101-4, 2001.

Moteki, N. and Kondo, Y.: Effects of mixing state on black carbon measurements by laser-induced incandescence, Aerosol Sci. Technol., 41, 398-417, doi:10.1080/02786820701199728, 2007.

Moteki, N. and Kondo, Y.: Dependence of laser-induced incandescence on physical properties of black carbon aerosols: measurements and theoretical interpretation, Aerosol Sci. Technol., 44, 663-675, doi:10.1080/02786826.2010.484450, 2010.

Moteki, N., Kondo, Y., Takegawa, N., and Nakamura, S.: Directional dependence of thermal emission from nonspherical carbon particles, J. Aerosol Sci., 40, 790-801, doi:10.1016/j.jaerosci.2009.05.003, 2009.

Mulholland, G. W. and Mountain, R. D.: Coupled dipole calculation of extinction coefficient and polarization ratio for smoke agglomerates, Combust. Flame, 119, 56-68, doi:10.1016/S00102180(99)00035-8, 1999.

Müller, T., Henzing, J. S., de Leeuw, G., Wiedensohler, A., Alastuey, A., Angelov, H., Bizjak, M., Collaud Coen, M., Engström, J. E., Gruening, C., Hillamo, R., Hoffer, A., Imre, K., Ivanow, P., Jennings, G., Sun, J. Y., Kalivitis, N., Karlsson, H., Komppula, M., Laj, P., Li, S. M., Lunder, C., Marinoni, A., Martins dos Santos, S., Moerman, M., Nowak, A., Ogren, J. A., Petzold, A., Pichon, J. M., Rodriquez, S., Sharma, S., Sheridan, P. J., Teinilä, K., Tuch, T., Viana, M., Virkkula, A., Weingartner, E., Wilhelm, R., and Wang, Y. Q.: Characterization and intercomparison of aerosol absorption photometers: result of two intercomparison workshops, Atmos. Meas. Tech., 4, 245-268, doi:10.5194/amt-4-245-2011, 2011.

Mullins, J. and Williams, A.: The optical properties of soot: a comparison between experimental and theoretical values, Fuel, 66, 277-280, doi:10.1016/0016-2361(87)90255-9, 1987.

Olfert, J. S., Symonds, J. P. R., and Collings, N.: The effective density and fractal dimension of particles emitted from a light-duty 
diesel vehicle with a diesel oxidation catalyst, J. Aerosol Sci., 38, 69-82, doi:10.1016/j.jaerosci.2006.10.002, 2007.

Onasch, T. B., Trimborn, A., Fortner, E. C., Jayne, J. T., Kok, G. L., Williams, L. R., Davidovits, P., and Worsnop, D. R.: Soot particle aerosol mass spectrometer: development, validation, and initial application, Aerosol Sci. Technol., 46, 804-817, doi:10.1080/02786826.2012.663948, 2012.

Park, K., Cao, F., Kittelson, D. B., and McMurry, P. H.: Relationship between particle mass and mobility for diesel exhaust particles, Environ. Sci. Technol., 37, 577-583, doi:10.1021/es025960v, 2003.

Park, K., Kittelson, D. B., Zachariah, M. R., and McMurry, P. H.: Measurement of inherent material density of nanoparticle agglomerates, J. Nanopart. Res., 6, 267-272, doi:10.1023/B:NANO.0000034657.71309.e6, 2004.

Robers, W., Schröder, H., Kompa, K. L., and Niessner, R.: Photo- und Thermoionisation von Aerosolen durch gepulstes Laserlicht, Z. Phys. Chem. Neue Fol., 159, 129-148, doi:10.1524/zpch.1988.159.Part_2.129, 1988.

Roth, C., Ferron, G. A., Karg, E., Lentner, B., Schumann, G., Takenaka, S., and Heyder, J.: Generation of ultrafine particles by spark discharging, Aerosol Sci. Technol., 38, 228-235, doi:10.1080/02786820490247632, 2004.

Schmid, H., Laskus, L., Abraham, H. J., Baltensperger, U., Lavanchy, V., Bizjak, M., Burba, P., Cachier, H., Crow, D., Chow, J., Gnauk, T., Even, A., ten Brink, H. M., Giesen, K.P., Hitzenberger, R., Hueglin, C., Maenhaut, W., Pio, C., Carvalho, A., Putaud, J.-P., Toom-Sauntry, D., and Puxbaum, H.: Results of the "carbon conference" international aerosol carbon round robin test stage I, Atmos. Environ., 35, 2111-2121, doi:10.1016/S1352-2310(00)00493-3, 2001.

Schmid, J., Grob, B., Niessner, R., and Ivleva, N. P.: Multiwavelength Raman microspectroscopy for rapid prediction of soot oxidation reactivity, Anal. Chem., 83, 1173-1179, doi:10.1021/ac102939w, 2011.

Schnaiter, M., Horvath, H., Möhler, O., Naumann, K.-H., Saathoff, H., and Schöck, O. W.: UV-VIS-NIR spectral optical properties of soot and soot-containing aerosols, J. Aerosol Sci., 34, 14211444, doi:10.1016/S0021-8502(03)00361-6, 2003.

Schnaiter, M., Gimmler, M., Llamas, I., Linke, C., Jäger, C., and Mutschke, H.: Strong spectral dependence of light absorption by organic carbon particles formed by propane combustion, Atmos. Chem. Phys., 6, 2981-2990, doi:10.5194/acp-6-2981-2006, 2006.

Schneider, J., Weimer, S., Drewnick, F., Borrmann, S., Helas, G., Gwaze, P., Schmid, O., Andreae, M. O., and Kirchner, U.: Mass spectrometric analysis and aerodynamic properties of various types of combustion-related aerosol particles, Int. J. Mass Spectrom., 258, 37-49, doi:10.1016/j.ijms.2006.07.008, 2006.

Schuster, M. E., Hävecker, M., Arrigo, R., Blume, R., Knauer, M., Ivleva, N. P., Su, D. S., Niessner, R., and Schlögl, R.: Surface sensitive study to determine the reactivity of soot with the focus on the European emission standards IV and VI, J. Phys. Chem., 115, 2568-2580, doi:10.1021/jp1088417, 2011.
Schwarz, J. P., Spackman, J. R., Gao, R. S., Perring, A. E., Cross, E., Onasch, T. B., Ahern, A., Wrobel, W., Davidovits, P., Olfert, J., Dubey, M. K., Mazzoleni, C., and Fahey, D. W.: The detection efficiency of the single particle soot photometer, Aerosol Sci. Technol., 44, 612-628, doi:10.1080/02786826.2010.481298, 2010.

Shindell, D., Kuylenstierna, J. C. I., Vignati, E., van Dingenen, R., Amann, M., Klimont, Z., Anenberg, S. C., Muller, N., JanssensMaenhout, G., Raes, F., Schwartz, J., Faluvegi, G., Pozzoli, L., Kupiainen, K., Höglund-Isaksson, L., Emberson, L., Streets, D., Ramanathan, V., Hicks, K., Oanh, N. T. K., Milly, G., Williams, M., Demkine, V., and Fowler, D.: Simultaneously mitigating near-term climate change and improving human health and food security, Science, 335, 183-189, doi:10.1126/science.1210026, 2012.

Slowik, J. G., Stainken, K., Davidovits, P., Williams, L. R., Jayne, J. T., Kolb, C. E., Worsnop, D. R., Rudich, Y., DeCarlo, P. F., and Jimenez, J. L.: Particle morphology and density characterization by combined mobility and aerodynamic diameter measurements. Part 2: Application to combustion-generated soot aerosols as a function of fuel equivalence ratio, Aerosol Sci. Technol., 38, 1206-1222, doi:10.1080/027868290903916, 2004.

Slowik, J. G., Cross, E. S., Han, J.-H., Davidovits, P., Onasch, T. B., Jayne, J. T., Williams, L. R., Canagaratna, M. R., Worsnop, D. R., Chakrabarty, R. K., Moosmüller, H., Arnott, W. P., Schwarz, J. P., Gao, R.-S., Fahey, D. W., Kok, G. L., and Petzold, A.: An inter-comparison of instruments measuring black carbon content of soot particles, Aerosol Sci. Technol., 41, 295-314, doi:10.1080/02786820701197078, 2007.

Stephens, M., Turner, N., and Sandberg, J.: Particle identification by laser-induced incandescence in a solid-state laser cavity, Appl. Opt., 42, 3726-3736, doi:10.1364/AO.42.003726, 2003.

Su, Y. X., Sipin, M. F., Prather, K. A., Gelein, R. M., Lunts, A., and Oberdorster, G.: ATOFMS characterization of individual model aerosol particles used for exposure studies, Aerosol Sci. Technol., 39, 400-407, doi:10.1080/027868290946694, 2005.

Swietlicki, E., Hansson, H.-C., Hämeri, K., Svenningsson, B., Massling, A., McFiggans, G., McMurry, P. H., Petäjä, T., Tunved, P., Gysel, M., Topping, D., Weingartner, E., Baltensperger, U., Rissler, J., Wiedensohler, A., and Kulmala, M.: Hygroscopic properties of submicrometer atmospheric aerosol particles measured with H-TDMA instruments in various environments - a review, Tellus, 60B, 432-469, doi:10.1111/j.16000889.2008.00350.x, 2008.

Weingartner, E., Burtscher, H., and Baltensperger, U.: Hygroscopic properties of carbon and diesel soot particles, Atmos. Environ., 31, 2311-2327, doi:10.1016/S1352-2310(97)00023-X, 1997.

Wentzel, M., Gorzawski, H., Naumann, K.-H., Saathoff, H., and Weinbruch, S.: Transmission electron microscopical and aerosol dynamical characterization of soot aerosols, J. Aerosol Sci., 34, 1347-1370, doi:10.1016/S0021-8502(03)00360-4, 2003. 